\title{
Bioética ambiental: concepção de estudantes universitários sobre o uso de animais para consumo, trabalho, entretenimento e companhia
}

\author{
Environmental bioethics: college students' conception \\ of the use of animals for food, work, entertainment \\ and company purposes
}

Marta Luciane Fischer ${ }^{1}$ • Priscilla Regina Tamioso ${ }^{2}$

\begin{abstract}
Resumo: A sociedade demanda novos paradigmas éticos para pautar suas decisões quanto ao uso de animais. A intermediação do diálogo entre a dimensão cultural, social e pessoal requer a intervenção de ferramentas como a Bioética ambiental. Objetivou-se caracterizar a concepção de estudantes universitários sobre o uso de animais a fim de fornecer subsídios para programas de educação ambiental. Para tal, foram conduzidas 87 entrevistas quanto à concepção emocional e cultural, e o posicionamento ético no uso de animais para alimentação, vestimenta, trabalho, entretenimento e companhia. As análises indicam, além da tendência contemporânea de respeito na relação ser-humano/animal, que o posicionamento ético possui maior relação com a finalidade do que pela afinidade profissional. Fato que demanda a elaboração de programas que ultrapassem a mera informação e sensibilização, estimulando a discussão desses temas no ensino de ciências, a fim de capacitar o aluno na tomada de decisões e, assim, exercer a cidadania plena.
\end{abstract}

Palavras-chave: Bem-estar animal. Bioética. Ética animal. Educação ambiental.

\begin{abstract}
Society needs new ethical guidelines to underlie their decisions regarding the use of animals. However, the dialogue between the cultural, social and personal dimensions requires the intervention of tools such as Environmental Bioethics. This study aimed to characterize the conception of the use of animals of college students in order to provide grants for environmental education programs. We were conducted 87 interviews on the emotional and cultural conception, and their ethical position on the use of animals for food, vestment, work, entertainment and company. The analysis indicates that part of the contemporary tendency towards respect involved the human/animal relationship, that their ethical positions indicated a greater relationship with the purpose then with the professional affinity. This demands the development of intervention programs through information and awareness, in order to encourage the discussion of these subjects in science education, for the purpose of enabling students in making decisions and exercising full citizenship.
\end{abstract}

Keywords: Animal welfare. Bioethics. Animal ethics. Environmental education.

\footnotetext{
${ }^{1}$ Pontifícia Universidade Católica do Paraná (PUCPR), Programa de Pós-Graduação em Bioética, Curitiba, PR, Brasil. E-mail: < fischer.mrt@gmail.com>

${ }^{2}$ Universidade Federal do Paraná (UFPR), Laboratório de Bem-estar Animal, Curitiba, PR, Brasil.
} 


\section{Introdução}

O questionamento da idoneidade das condutas humanas direcionadas à natureza esteve, inicialmente, atrelado à percepção das atitudes dos homens em relação aos animais, caracterizando alguns dos primeiros dilemas éticos. O convívio natural entre o Homo sapiens e os demais animais foi alterado há 10.000 anos, com o advento da agricultura e consequente domínio de animais e plantas (MORRIS, 1990). A aceitação do uso de animais, sobretudo na experimentação, foi consolidada durante a revolução científica cuja visão mecanicista, defendida pioneiramente por Descartes (COELHO, 2012), foi plenamente incorporada no meio acadêmico, passando o antropomorfismo a ser veementemente reprimido, contribuindo, assim, para, paulatinamente, o distanciamento afetivo dos animais (FISCHER; OLIVEIRA, 2012).

Atualmente, a ética com relação ao uso de animais ainda está centrada no debate da utilização acadêmica e educacional, reflexo da consolidação da bioética clínica e elaboração de regras para o uso do sujeito humano em pesquisa (FISCHER; TAMIOSO, 2013; SILLA et al., 2010). A legislação brasileira (BRASIL, 2008) ordena que toda instituição de pesquisa que use animais institua uma Comissão de Ética que se responsabilize pelo cumprimento da legislação alicerçada no princípio dos "três erres", ou seja: que se considere a possibilidade de se substituir o modelo experimental por outro com menor senciência (replacement); que se reduza o número de animais ao mínimo justificável (reduction), e que haja investimento em tecnologia para refinar a manipulação, a fim de se causar o menor sofrimento possível aos animais (refine) (TINOCO, 2008). Já para os demais usos, a normatização se pauta na Constituição Federal (BRASIL, 1988) e na lei de crimes ambientais (BRASIL, 1998), as quais criminalizam os atos de crueldade contra os animais. Essa abordagem genérica pode propiciar interpretações dúbias, endossando práticas discutíveis, como: a exposição de animais, reprodução seletiva, eutanásia, animais utilizados em rituais religiosos e zoofilia.

A sociedade demanda novos paradigmas éticos para tomada de decisões, os quais, devido à aglutinação de regras de conduta oriundas da globalização, dependem da interferência da bioética ambiental como mediadora do diálogo entre a complexa dimensão cultural, social e pessoal (MUÑOZ, 2004). O posicionamento da sociedade diante do uso dos animais conduzirá o rumo das condutas morais e da atuação do poder público, pois possui alto potencial de influência na legislação, economia, políticas de sustentabilidade e nos setores socioeconômicos (COLEMAN; HAY, 2004). A forma como diferentes profissionais tratam os animais é extremamente importante para o desenvolvimento de programas de educação, por meio da utilização de diferentes inferências e aplicação de instrumentos diversificados, cuja atuação em distintas frentes adequadas a um público diverso, vise conscientizar todos os segmentos da sociedade da necessidade de procedimentos éticos no uso dos animais. Embora ocorram, na literatura, inúmeros diagnósticos da percepção sobre o uso de animais em pesquisa, pouco foi explorado sobre os demais papéis exercidos pelos animais na sociedade. Além disso, ressaltase a importância de diagnósticos locais para promoção de intervenções educacionais, seja no ensino formal ou não formal, de base ou técnico, que atendam demandas sociais específicas. Nesse contexto, é fundamental o diagnóstico da concepção sobre uso de animais por diferentes setores da sociedade, dentre os quais se destaca o meio universitário, pois, além de reunir público heterogêneo, resultado da educação básica formal e não formal (PHILLIPS; MCCULLOUGH, 2005), visa ao desenvolvimento e aprimoramento de habilidades e competências essenciais para 
a formação e atuação profissional. Fischer e Tamioso (2013) verificaram que o posicionamento diante do uso científico e acadêmico de animais apresentou pouca relação com a área de formação profissional; e, embora acadêmicos dos cursos da área biológica tenham demonstrado mais conhecimento técnico, predominou a visão mecanicista e utilitarista. Assim, objetivou-se caracterizar a concepção de estudantes universitários sobre o uso de animais para consumo, trabalho, entretenimento e companhia, a fim de fornecer subsídios para programas de educação ambiental e contribuir com a formação de cidadãos mais conscientes.

\section{Relação entre humanos e animais}

O ser humano contemporâneo utiliza diferentes paradigmas éticos para mediar sua relação com os animais, muitas vezes, adaptando as concepções conforme o valor atribuído. Tradicionalmente, a sociedade aplica o paradigma, ou seja, um modelo balizador de conduta, conforme um viés antropocêntrico e antropológico, não atribuindo, ao animal, valor inerente, mas meramente instrumental, utilitarista e econômico (FELIPE, 2006a, 2006b; TINOCO, 2008). Jeremy Bentaham e John Stuart Mill, no século XVIII, foram pioneiros na promoção da visão contrária, propondo a expansão do universo da consideração moral e aplicação de caráter hedonista aos animais. Entretanto, foi na atualidade, com o filósofo Peter Singer, que esta visão ganhou força. A teoria moral consequencialista considera a capacidade de sofrer como um dos critérios morais mais relevantes, necessitando, para tal, da senciência, faculdade mental que possibilita a consciência da dor física e mental e geradora de interesses em não sofrer (SINGER, 2004). Todavia, a ética utilitarista admite como moralmente aceitável o abate de alguns animais, desde que seja justificável e realizado de forma rápida e indolor (SILVA, 2012). Não obstante, os critérios de quem e como ser abatido têm gerado posicionamentos conflitantes entre diferentes sujeitos/atores da sociedade. A preocupação com o sofrimento desencadeou o surgimento da ética bem-estarista, exercida, sobretudo, por cientistas e agricultores, a qual visa propiciar boas condições de vida para os animais que, todavia, necessitam ser mantidos cativos sob a tutela do homem. Essa ética é socialmente percebida como moderada, razoável, reducionista e interessada em trabalhar dentro e com o sistema de forma racional e com bom senso, buscando na informação e na ciência os elementos para embasar a avaliação moral (SILVA, 2012). Concomitantemente, uma visão antagônica, inspirada em Kant, deu origem à ética do direito animal ou abolicionista, liderada por Tom Regan. Tal visão considera que os animais possuem um único direito moral: não ser prejudicado devido às necessidades utilitaristas da sociedade (REGAN, 2006). Desta forma, deve-se evitar causar danos dentro de uma escala de valores, sugerindo que os sujeitos de consideração moral são aqueles que possuem valor intrínseco e que sejam "sujeitos-de-sua-vida" capazes de diferenciar experiências de prazer e de dor (FELIPE, 2006b). Essa ética é socialmente encarada como extremista, abolicionista, violenta e libertária, atuando, emocional e irracionalmente, desvinculada dos dados científicos (SILVA, 2012).

As atitudes da população com relação aos animais divergem de acordo com a sua função e características, sendo os mesmos categorizados de acordo com: utilidade, sensibilidade, periculosidade e importância (DRISCOLL, 1995; KNIGHT et al., 2004, 2009), senciência para dor e aflição (KNIGHT et al., 2004, 2009; PHILLIPS, 2007; PHILLIPS; MCCULLOUGH, 2005; PLOUS, 1993), grau de cognição (KNIGHT et al., 2004, 2009), estética e afetividade (KELLERT; BERRY, 1982) e táxon (KNIGHT et al., 2004). Diferenças no posicionamento 
têm sido relacionadas com aspectos individuais, como gênero (HERZOG; GOLDEN, 2009; KNIGHT et al., 2004; NICKELL; HERZOG, 1996; PHILLIPS; MCCULLOUGH, 2005) e idade (KNIGHT et al., 2004); sociais, tais como: nacionalidade (PIFER, 1996), envolvimento em atividades pró-animal (SIGNAL; TAYLOR, 2007) e ideologia ética (NICKELL; HERZOG, 1996); e subjetivos, como: atenção, ansiedade, sugestão e experiência (KNIGHT et al., 2004; PHILLIPS, 2007), hábito alimentar (KNIGHT et al., 2004), local de moradia (KNIGHT et al., 2004) e área de atuação (KNIGHT et al., 2009). Segundo Coelho (2002), a sociedade contemporânea tem mostrado um crescente interesse pela forma como animais selvagens e domésticos são tratados, estando o mesmo atrelado, sobretudo, à mudança de concepção de mente da ótica criacionista para a evolucionista. Segundo o autor, a convivência com os animais favorece a relação afetiva e a identificação com seu comportamento, mesmo não sendo essa compreensão determinante para a prevalência de atitudes altruísticas em detrimento dos maus-tratos, o que demanda a reflexão sobre as obrigações e responsabilidades dos agentes morais e respeito ao direito dos sujeitos morais.

\section{Relação entre a área de formação profissional e a concepção dos animais}

O curso de formação profissional também pode influenciar na percepção do animal (PHILLIPS, 2007). Enquanto estudantes de ciência animal reconhecem a necessidade de se evitar a dor, não consideram o sistema de criação como danoso, indicando aceitação ou insensibilidade às técnicas, priorizando a segurança alimentar em detrimento do bem-estar animal (NORDSTROM et al., 2000). Já estudantes de medicina veterinária acreditam que a capacidade cognitiva é maior nas espécies domésticas, embora não haja evidências anatômicas e fisiológicas (PHILLIPS; MCCULLOUGH, 2005). Analogicamente, cientistas tendem a ser mais resistentes à crença de que animais possuam processos mentais complexos, consequência do repúdio ao antropomorfismo (KNIGHT et al., 2009). O aumento do conhecimento (KNIGHT et al., 2004) e o poder econômico (DAVEY, 2006) têm diminuído o apoio a procedimentos tradicionalmente aceitos, surgindo, no cenário social, o papel dos ativistas. Embora Herzog e Golden (2009) não tenham encontrado relação evidente entre moralidade e ativismo, Signal e Taylor (2007) afirmaram que cidadãos envolvidos na proteção animal são mais empáticos aos animais. Serpell (2004), revisando estudos sobre percepção, identificou dois determinantes motivacionais primários: afeto e utilidade, ambos possíveis de serem afetados por: atributos específicos dos animais, características individuais, experiências, fatores, normas e condutas culturais (HAIDT, 2001). Nickell e Herzog (1996) ressalvam que a relação entre atitudes e comportamentos é complexa, havendo uma diferença entre o que os indivíduos acreditam e o que fazem. É possível que a predisposição para orientação moral direcione o envolvimento em causas sociais, contudo, é importante avaliar os paradigmas éticos para se verificar o nível de comprometimento de grupos específicos.

Considerando a possibilidade da maior proximidade afetiva com o objeto de estudo ser a norteadora da decisão profissional, e partindo da premissa que a maior ou menor proximidade com os animais pode ser resultado da educação formal recebida no Ensino Fundamental e Médio, bem como dos programas de educação não formal dos quais oportunizados ao estudante, foi conduzida, no período de fevereiro de 2008 a setembro de 2010, uma avaliação da concepção de estudantes de diferentes cursos de graduação do campus Curitiba da Pontifícia Universidade 
do Paraná (PUCPR). A fim de se obter uma amostra aleatória e homogênea, a determinação dos entrevistados foi realizada com base nas cinco áreas do saber da PUCPR, sendo obtida por sorteio uma amostragem de 30\% dos cursos disponíveis em cada escola: Escola de Saúde e Biociências (ESB: Enfermagem, Fisioterapia e Psicologia), Escola de Educação e Humanidades (CEH: Filosofia, Educação Física - Bacharelado, Letras - Português e Pedagogia), Escola de Negócios (EN: Ciências Contábeis), Escola Politécnica (EP: Sistemas de Informação, Matemática (licenciatura), Engenharia Civil, Engenharia Mecânica e Engenharia Química) e Escola de Comunicação e Artes (ECA: Comunicação Social-Publicidade e Propaganda e Serviço Social). O curso de Ciências Biológicas não foi incluído no sorteio da ESB, uma vez que, devido à inerente proximidade com animais, as respostas de alunos do bacharelado e licenciatura foram consideradas como ponto de comparação com os demais cursos. Foi entrevistado, aleatoriamente, um aluno de cada ano do respectivo curso, totalizando, assim, 17 cursos e 87 entrevistados. A entrevista estruturada foi composta por 14 questões para caracterização do público e 38 relacionadas à concepção emocional e cultural, e o posicionamento ético no uso de animais para alimentação, vestimenta, trabalho, entretenimento e companhia. O projeto foi aprovado pelo Comitê de Ética em Pesquisa (CEP) da PUCPR (nº 0002344/08). Os valores absolutos das respostas de cada questão foram comparados em uma mesma área de conhecimento por meio do teste qui-quadrado, sob nível de confiança de $95 \%(\mathrm{P}<0,05)$, a fim de se verificar se havia diferenças significativas entre os grupos, considerando, como hipótese nula, a homogeneidade da amostra. Para as questões abertas, foram efetuadas categorizações utilizando-se a técnica de Bardin (1982).

A análise da concepção dos acadêmicos do Ensino Superior evidenciou que a postura diante do animal tem relação maior com a finalidade do uso do que com a área de formação. Sendo a maioria das atitudes favoráveis aos animais $(88,5 \%)$ vinculadas, sobretudo, a sentimentos $\left(\chi_{(2)}^{2}=100,13, \mathrm{P}<0,01\right)$. Porém, identifica-se nitidamente a visão antropocêntrica, ao se enfatizar a existência de diferenças óbvias entre humanidade e animais $(89,6 \%)\left(\chi_{(1)}^{2}=54,7\right.$; $\mathrm{P}<0,01)$, pautadas na atribuição do raciocínio $(72,1 \%)$, negligenciando semelhanças, como emoções, sentimentos e consciência da dor, as quais deveriam ser suficientes para alcançar o almejado respeito na relação ser humano/animal, destacado pela maioria dos alunos $(63,2 \%)$ $\left(\chi_{(2)}^{2}=88,5 ; \mathrm{P}<0,01\right)$. Os acadêmicos da ESB exibiram posicionamento mais enfático com relação à ilegitimidade do domínio da humanidade sobre os animais, mas, assim como a maioria dos entrevistados que mostra compreender e identificar maus-tratos, parecem ter dificuldades de transformar pensamentos em atitudes, uma vez que, embora mais da metade dos respondentes tenha presenciado casos de maus-tratos contra animais, especialmente relacionados à agressão física $(71,1 \%)\left(\chi_{(8)}^{2}=721,6 ; \mathrm{P}<0,01\right)$ e em cães $(67 \%)\left(\chi_{(3)}^{2}=28,5 ; \mathrm{P}<0,01\right)$, a maioria $(71,1 \%)$ afirmou não ter coibido a ação $\left(\chi_{(1)}^{2}=9,3 ; \mathrm{P}<0,01\right)$. Assim, fatores como temor à represália e ridicularização influenciam na decisão em se posicionar diante de um ato considerado errado.

\section{Animais utilizados para alimentação}

A associação do consumo de carne aos bovinos é reflexo cultural, direcionando a valoração para as demais espécies. A relação entre humanos e animais de produção é inevitavelmente desigual, uma vez que o manejo visa lucros e benefícios decorrentes da melhora do desempenho do animal ou do cumprimento legal (PHILLIPS; MCCULLOUGH, 2005). Os 
próprios profissionais se mostram tolerantes às práticas zootécnicas, mesmo cientes de que causam dor ou desconforto (PHILLIPS, 2007). Embora a população manifeste o desejo de que os animais de produção sejam bem tratados e que sua vida seja finalizada humanitariamente, o discurso não reflete na atitude, uma vez que não há incentivo por produtos certificados. Em geral, a sociedade reduz o conflito ético ao considerar o consumo de animais uma necessidade biológica, além de se conformar com a ausência de opções (PLOUS, 1993).

O grupo analisado igualmente revelou visão tradicionalista em relação ao uso de animais para o consumo, reflexo da ausência de maiores dilemas éticos da sociedade diante dessa temática (PETROIANU, 1996). A maioria dos entrevistados considera correto o uso de animais para a alimentação humana, destacando-se os bovinos (ESB e EP). Entretanto, parte dos respondentes, predominantemente da ESB, reconhece que os animais são maltratados em todas as etapas da produção, e acredita que alimentos de origem vegetal, tais como leguminosas, podem substituir os de origem animal (Tabela 1). Justamente a inconsistência desta questão

Tabela 1. Frequência relativa das respostas para as perguntas a respeito do uso de animais para alimentação pelo total dos entrevistados, bem como dos relativos às áreas do saber

Total ESB EP EEH EN ECA

\section{Ética}

Consideram correto o uso de animais para alimentação

Consideram a existência de maus-tratos

\section{Consumo}

Citam os bovinos como animais de consumo

Citam os suínos como animais de consumo

Citam as aves como animais de consumo

Citam os peixes como animais de consumo

Citam outros animais de consumo (ovinos, equinos, rãs,

camarão, qualquer animal que não em extinção)

\section{Substituição}

Consideram possível a substituição de alimentos de origem animal

Acreditam na substituição por leguminosas

Acreditam na substituição por outros itens (frutas, grãos,

fibras, dieta balanceada, todos em combinação, proteínas sintéticas)

Discordam da substituição, pela obtenção insuficiente de proteínas

Discordam da substituição, por gostarem do sabor

Discordam da substituição, pela falta de opções

Discordam da substituição, por outros motivos (impossível

$\begin{array}{rrrrrr}84^{*} & 80,7^{*} & 96^{*} & 78^{*} & 80^{*} & 60^{*} \\ 49,4 & 61,5^{*} & 41 & 47 & 50 & 40 \\ & & & & & \\ 34^{*} & 29,5^{*} & 36^{*} & 38 & 33 & 33 \\ 20,3 & 19,7 & 21,7 & 7,2 & 20,8 & 22,2 \\ 25,5 & 27,8 & 23 & 11,6 & 25 & 22,2 \\ 13,5 & 18 & 10,1 & 4,3 & 16,7 & 11,1 \\ 6,7 & 4,9 & 8,7 & 2,8 & 4,1 & 11,1\end{array}$

a produção em larga escala; falta de pesquisas; alimentação

$\begin{array}{rrrrrr}59 & 54 & 48 & 74^{*} & 70^{*} & 60 \\ & & & & & \\ 75,9^{*} & 72,2^{*} & 77^{*} & 70,5^{*} & 100^{*} & 75^{*} \\ 24,1 & 27,8 & 23 & 29,5 & 0 & 25\end{array}$

carnívora faz parte da cadeia alimentar)

Os valores absolutos foram comparados a fim de se testar a homogeneidade nas respostas por meio do teste qui-quadrado, sendo os valores significativamente diferentes $(\mathrm{P}<0,05)$ acompanhados de asterisco.

Fonte: elaborada pelos autores. 
ética envolvida no uso de animais para consumo leva a diferenciação na moral intuitiva ser um dos motivos que torna o debate do direito animal fugaz, uma vez que, até mesmo muitos dos mais ativos e sensíveis defensores dos direitos animais, consomem carne (HERZOG; GOLDEN, 2009). A elevada frequência de consumo de carne e derivados, evidenciada na pesquisa, provavelmente está relacionada ao amplo, acessível e diversificado mercado nacional (GAGLEAZZI et al., 2002). Embora o consumo de carne e tutano tenha sido fundamental para o crescimento e evolução do cérebro do H. sapiens (ZIMMER, 2003), estudos têm comprovado efeitos nocivos no consumo exagerado (doenças coronárias, diabetes, osteoporose, neoplasias) e dos elevados custos ecológico e espacial, indicando que a substituição é possível (ARAGÃO, 2006). Os entrevistados reconhecem as alternativas, porém, reproduzem as crenças relacionadas à desnutrição e ressaltam a satisfação sensorial e o contexto natural da cadeia alimentar, despreocupando-se efetivamente com o bem-estar dos animais, argumentando que a morte para consumo é a justificativa da sua existência. A nítida desinformação faz parte do cotidiano dos consumidores, que, na maioria das vezes, preferem se abster de maiores informações, uma vez que estas desencadeiam desconforto, sobretudo por serem expostas de maneira simplista e fortemente carregada de emoções (HÖTZEL; MACHADO FILHO, 2004). Assim, o produto final é apresentado de forma que não haja associação com o animal vivo (WEBSTER, 2005). Contudo, gradativamente, a ciência tem comprovado a senciência dos animais e as consequências dos maus-tratos, fato que vem subsidiando o desenvolvimento de legislação e técnicas de bem-estar animal nos sistemas de produção (BROOM; FRASER, 2010).

\section{Animais usados para vestimenta}

Muitas pessoas não veem inconsistência ética em usar produtos de couro ou lã, por serem resultado da exploração de animais originalmente usados na alimentação, sendo uma destinação útil para um produto que, inevitavelmente seria descartado. Por outro lado, as peles se tornaram acessórios ultrapassados, provavelmente, reflexo dos movimentos pró-animal de repercussão internacional, bem como devido à eficácia e ao preço dos materiais sintéticos (REGAN, 2006). Logo, o fato de a maioria dos entrevistados reconhecerem as questões éticas envolvidas no uso de animais para vestimentas/acessórios (Tabela 2) leva ao questionamento se essas respostas refletem conhecimento e conscientização ou se são reflexo de uma conduta politicamente correta, explorada há muitos anos pela mídia. Ressalta-se a importância de se estimular, nas próximas discussões éticas, o custo ambiental do processamento desses materiais.

\section{Animais usados para trabalho}

A sociedade aceita e até estimula a utilização de animais para trabalho, sobretudo, como meios de transporte, uma vez que foram a base do desenvolvimento econômico e tecnológico da humanidade (PETROIANU, 1996). Mesmo diante de todo o avanço da urbanização, o sustento de mais da metade da população mundial ainda depende dos animais de carga (WORLD ANIMAL PROTECTION BRASIL, 2007). 
Tabela 2. Frequência relativa das principais respostas para as perguntas a respeito do uso de animais para vestimenta pelo total dos entrevistados, bem como dos relativos às áreas do saber

\begin{tabular}{lrrrrrr}
\hline & Total & ESB & EP & EEH & EN & ECA \\
\hline Ética & & & & & & \\
$\quad$ Não consideram correto o uso de derivados animais & $84^{*}$ & $85^{*}$ & $78^{*}$ & $94^{*}$ & $90^{*}$ & $100^{*}$ \\
$\quad$ para confecção de vestimentas e acessórios & & & & & & \\
$\quad$ Consideram a existência de maus-tratos na criação & $60^{*}$ & $54^{*}$ & $67^{*}$ & $58^{*}$ & $70^{*}$ & 40 \\
Consumo & & & & & & \\
$\quad$ Disseram não possuírem vestimentas de origem animal & $67^{*}$ & $61,5^{*}$ & $70^{*}$ & $68,4^{*}$ & $70^{*}$ & 60 \\
$\quad$ Disseram não possuírem vestimentas de couro & $72^{*}$ & $69^{*}$ & $100^{*}$ & 83 & 50 & 33,3 \\
$\quad$ Disseram não possuírem vestimentas de lã, pele ou & 28 & 31 & 0 & 17 & 50 & 66,6 \\
penugem & & & & & & \\
Substituição & & & & & & \\
$\quad \begin{array}{l}\text { Disseram saber de qual animal provém a sua roupa } \\
\text { Consideram as vestimentas sintéticas eficazes }\end{array}$ & $75^{*}$ & $77^{*}$ & $87,5^{*}$ & $33,3^{*}$ & $83,3^{*}$ & $100^{*}$ \\
\hline
\end{tabular}

Os valores absolutos foram comparados a fim de se testar a homogeneidade nas respostas por meio do teste qui-quadrado, sendo os valores significativamente diferentes $(\mathrm{P}<0,05)$ acompanhados de asterisco.

Fonte: elaborada pelos autores.

Estima-se que cerca de trezentos milhões de animais são utilizados para tração e geração de força em países em desenvolvimento, movimentando uma economia de bilhões de dólares e promovendo a agropecuária familiar (WORLD ANIMAL PROTECTION BRASIL, 2007). Embora se utilizem, para transporte, gado, búfalo, mula, camelo, lhama, iaque, burro, elefante e cão (RAMASWAMY, 1998), o cavalo é o mais explorado. O uso de cavalos para coleta de recicláveis é uma realidade de diversas cidades, gerando uma importante questão de cunho ético (OLIVEIRA et al., 2007). Os maus-tratos, muitas vezes dispensados não intencionalmente, são geralmente negligenciados, estando atrelados aos diversos outros problemas das sociedades modernas, tais como: exclusão social, leis de trânsito, trabalho infantil, pobreza, ignorância e destinação incorreta dos entulhos (OLIVEIRA et al., 2007). Deve-se ressaltar que os próprios equídeos selecionados há milênios para desempenho de atividades de força não têm resistido à carga de trabalho exigida pelas demandas urbanas, demandando o conhecimento do padrão de locomoção específico da tração urbana a fim de se estabelecerem os limites de exigências fiscais (MARANHÃO et al., 2006), assim como a modernização do sistema por meio de: tecnologia e manejo, legislação, educação, capacitação e assistência veterinária (OLIVEIRA et al., 2007). A discordância dos entrevistados com o uso de animais para trabalho reflete provavelmente a associação com a função de carga na área rural e a desvinculação dessa categoria de uso animal com as emergentes polêmicas da exploração para serviços urbanos tais como: ferramenta militar e policial, cão-de-guarda, cão-guia e na zooterapia, e igualmente relacionados à desinformação, desinteresse e insensibilidade (PROJETO ESPERANÇA ANIMAL, 2015b) (Tabela 3). 
Bioética ambiental: concepção de estudantes universitários ...

Tabela 3. Frequência relativa das principais respostas para as perguntas a respeito do uso de animais para trabalho pelo total dos entrevistados, bem como dos relativos às áreas do saber

\begin{tabular}{lrrrrrr}
\hline & Total & ESB & EP & EEH & EN & ECA \\
\hline Ética & & & & & & \\
$\quad$ Não consideram correto o uso de animais para trabalho & 52 & 58 & 41 & 58 & 40 & 80 \\
$\quad$ Consideram maus-tratos & 40 & 50 & 41 & 37 & 20 & 40 \\
& & & & & & \\
Consumo & $42^{*}$ & $40^{*}$ & 37 & $52^{*}$ & 46 & 28,5 \\
$\quad$ Relacionaram animais de trabalho com carga & 23 & 22,9 & 31,4 & 18,5 & 7,7 & 28,5 \\
$\quad \begin{array}{l}\text { Relacionaram animais de trabalho com arado } \\
\text { Relacionaram animais de trabalho com guarda }\end{array}$ & 9,4 & 5,7 & 8,6 & 7,4 & 23 & 14,3 \\
$\quad$ Relacionaram animais de trabalho com transporte & 15,4 & 20 & 11,4 & 11,1 & 15,4 & 28,6 \\
$\quad \begin{array}{l}\text { Relacionaram animais de trabalho com outra finalidade } \\
\text { (desarmar bombas, pombo-correio, 8,33\% moer cana, }\end{array}$ & 10,3 & 11,4 & 11,4 & 11,1 & 7,7 & 0 \\
$\quad$ ordenha, auxílio a cegos, lavoura, circos e construção) & & & & & & \\
\hline
\end{tabular}

Fonte: elaborada pelos autores.

\section{Animais usados para o entretenimento}

O injustificável - ainda que aceitos e até estimulados pela sociedade - uso e subjugação de animais em circos, rodeios, farra-do-boi, vaquejadas, rinhas, espetáculos, caça, práticas esportivas e religiosas e zoológicos, tem levantado a discussão de questões éticas complexas (PETROIANU, 1996). Mesmo que exista legislação conservacionista, o peso cultural conduz para que sejam realizadas clandestinamente, justificadas como práticas culturais cujo divertimento sádico do ser humano demanda que o animal continue sendo tratado como objeto desprovido de dor, sensibilidade, ética ou respeito (CHALFUN, 2008). Embora de maneira geral os entrevistados tenham mostrado posicionamento contundente contra ao uso de animais para entretenimento, refletindo um repúdio inerente à futilidade da prática, também evidenciaram terem visão parcial da amplitude dessa utilização, generalizando o uso para exibições em shows (Tabela 4).

A experiência de presenciar espetáculos com animais em circos e o abandono recente da prática, pela maioria significativa dos entrevistados, evidenciam a influência do contexto cultural na tomada de decisão. Resultado este provavelmente reflexo de uma atuação, mesmo que ainda tímida, de ativistas e ONGs nesse segmento (PETROIANU, 1996). Apesar de a visão tradicional persistir, informações sobre as aversivas técnicas de manejo, confinamento, condicionamento por punição, redução do comportamento natural têm levado à demanda de substituição das performances animais pelo artista humano (REGAN, 2006). É possível que a exploração de animais a partir de outras mídias, tais como cinema, TV, internet e jogos, tenha suprido a necessidade de presenciar os espetáculos. Legalmente, o uso de animais em circos foi proibido em diversos estados brasileiros, contudo, apesar dos inerentes maus-tratos, práticas como o rodeio são mantidas sob uma motivação econômica e cultural (PROJETO ESPERANÇA ANIMAL, 2015a).

A limitação da compreensão da exploração animal para entretenimento ficou evidente na condenação aos circos, mas não na percepção da problemática envolvida no confinamento 
de animais para exposição nos zoológicos, criados com o propósito de expor espécies exóticas (SANDERS; FEIJÓ, 2007). Provavelmente, a diversidade de informações sobre a vida animal transmitida pelos documentários tem sensibilizado a sociedade, levando a cobrança por atitudes éticas, superando a demanda pública pela estética natural (MORRIS, 1990). Contudo, o ambiente artificial do cativeiro tem exposto, ao público, animais doentes e transfigurados, sendo os próprios visitantes fatores estressantes e desencadeadores de estereotipias e comportamentos agressivos, sobretudo pequenos primatas, que podem interpretá-los como predadores (AGORAMOORTHY, 2004). Deve-se considerar que as demandas conservacionistas e educacionais dos zoológicos ainda não conseguiram superar a visão tradicional de um local de recreação onde bons momentos em família são ilustrados por animais raros totalmente dominados pelo homem. Essa percepção, aliada ao desserviço promovido pela mídia, possibilitam que ocorram casos como o menino que teve seu braço dilacerado por um tigre no zoológico de Maringá por não conceber a natureza selvagem do animal (MEU pai..., 2014). A inviabilidade de eliminação dos zoológicos, pelo menos a curto e médio prazos, tem conduzido à busca de melhoria dos recintos, tornando-os mais enriquecidos e estimulantes e proporcionando melhores condições e bem-estar para os animais (MARINO et al., 2010). Até mesmo o impacto da concentração, densidade, atividade, tamanho, posição e barulho dos visitantes pode ser reduzido com estruturas que criem barreiras visuais, olfativas e sonoras (DAVEY, 2006). A cobrança da visitação é tida como uma solução pelos entrevistados, a fim de que os recursos possam ser direcionados para manutenção dos animais. Ressalva-se que essa prática já é exercida em inúmeras instituições e que, de fato, viabiliza tanto os programas de enriquecimento ambiental e educação ambiental e mudança na conduta ética, quanto de conservação ex-situ, reintrodução, pesquisa e expansão de parcerias no segmento do turismo. Segundo Marino et al. (2010), mundialmente, existem cerca de 12 mil zoológicos e parques, os quais atraem em torno de seiscentos milhões de visitantes, destes cerca de mil são reconhecidos pelas boas práticas no bem-estar animal.

\section{Animais usados para companhia}

Os benefícios dos animais de companhia para a saúde física e mental, sobretudo de crianças e idosos, têm sido amplamente enfatizados (AL-FAYEZ et al., 2003), porém, ainda são pouco compreendidas as razões pelas quais as pessoas confinam animais domésticos ou selvagens em suas moradias, uma vez que, paradoxalmente ao amor (PLOUS, 1993) e à busca por companhia, cerca de $60 \%$ dos cães vivem sós, apenas $10 \%$ dos tutores dispendem tempo para caminhadas diárias, o que resulta em danos físicos e psicológicos, tais como agressividade e ansiedade (STAFFORD, 2008). Portanto, uma atitude ética e responsável é esperada por parte de todos aqueles que possuem, ou desejam possuir animais de estimação. Já é possível perceber mudança social em que animais domésticos têm assumido o papel de membros das famílias e os selvagens, tradicionalmente usados para caça, agora são objetos de fascinação e explorados pelos programas de TV e parques selvagens (SANDOE; CHRISTIANSEN, 2009). Contudo, deve-se considerar que os animais elegidos para companhia estão vinculados a expressões culturais (AL-FAYEZ et al., 2003), sendo comum, em regiões tropicais, o confinamento de animais selvagens, o que gera outra questão ética contemporânea, cujo costume incentiva o tráfico de animais e diminuição de populações naturais, chegando a levar algumas espécies à extinção (GOMES; OLIVEIRA, 2013). 
Tabela 4. Frequência relativa das principais respostas para as perguntas a respeito do uso de animais para entretenimento pelo total dos entrevistados, bem como dos relativos às áreas do saber

Total ESB EP EEH EN ECA

\section{Ética}

Disseram não considerar correto o uso de animais para o entretenimento

Aprovaram a presença de animais em zoológicos

Aprovaram o uso de animais em circos

Aprovaram o uso de animais em outra atividade (esporte e safari)

\section{Problemas}

Consideram a domesticação forçada como maior problema

Consideraram o tratamento cruel como maior problema

Consideraram o sofrimento animal como maior problema

Consideraram a falta de ética, respeito e consciência como maiores problemas

Não souberam responder

\section{Consumo}

Já frequentaram locais de entretenimento com animais

Presenciaram animais em circos

Presenciaram animais em zoológicos

Não frequentam mais locais que usam animais

\section{Concepção de Zoológicos}

Consideraram como função dos Zoológicos a recuperação, conservação de espécies e educação ambiental

Consideraram como função dos Zoológicos o

entretenimento

Consideraram que os Zoológicos não deveriam existir

Consideraram outra função (recuperação de animais e

educação)

O Zoológicos deveriam ser pagos

$\begin{array}{llllll}70^{*} & 77^{*} & 59 & 84^{*} & 80^{*} \quad 20\end{array}$

$\begin{array}{llllll}37 & 57 & 33 & 50 & 0 & 20\end{array}$

$\begin{array}{llllll}27 & 14,3 & 25 & 50 & 0 & 40\end{array}$

$\begin{array}{llllll}37 & 29 & 0 & 0 & 100 & 40\end{array}$

Zoológicos deveriam ser pagos para arrecadar recursos para

$\begin{array}{llllll}11,3 & 5 & 12,5 & 6,2 & 3,33 & 0\end{array}$

$\begin{array}{llllll}24,8 & 50 & 20 & 25 & 22,2 & 0\end{array}$

$\begin{array}{llllll}14 & 20 & 6,2 & 18 & 11,1 & 0\end{array}$

$\begin{array}{llllll}44,4 & 20 & 50 & 44 & 3,33 & 0\end{array}$

os animais

Zoológicos deveriam ser pagos para arrecadar recursos para a conservação

Zoológicos deveriam ser pagos para arrecadar recursos para o entretenimento

$\begin{array}{rrrrrr}4,8 & 5 & 6,2 & 6,2 & 100 & 0 \\ 86^{*} & 88,4^{*} & 85^{*} & 89,4^{*} & 70^{*} & 100^{*} \\ 66^{*} & 63^{*} & 75^{*} & 59^{*} & 75^{*} & 50^{*} \\ 30,2 & 30 & 18 & 41 & 25 & 50 \\ 80^{*} & 74^{*} & 78^{*} & 76,4 & 100^{*} & 100^{*} \\ & & & & & \\ 36 & 25^{*} & 50 & 35 & 36 & 28 \\ & & & & & \\ 42 & 40^{*} & 40 & 35 & 43 & 71 \\ 36 & 0 & 50 & 35 & 36 & 29 \\ 17 & 35 & 5 & 23 & 7 & 0 \\ 65,5^{*} & 81^{*} & 63^{*} & 47^{*} & 70^{*} & 60^{*} \\ 87^{*} & 78^{*} & 100^{*} & 89^{*} & 86^{*} & 75^{*} \\ 5 & & & & & \\ 5 & 5 & 0 & 0 & 14,3 & 0 \\ 8,3 & 9 & 0 & 11,1 & 0 & 25\end{array}$

Os valores absolutos foram comparados a fim de se testar a homogeneidade nas respostas por meio do teste qui-quadrado, sendo os valores significativamente diferentes $(\mathrm{P}<0,05)$ acompanhados de asterisco.

Fonte: elaborada pelos autores.

A maioria dos entrevistados, sobretudo da ESB, possui, pelo menos, um animal de companhia, sendo citados até oito, predominando o cão. A justificativa passional foi a mais frequente, contudo, os entrevistados da ESB e EN foram os que relataram maiores frequências de outros motivos. Apesar de a maioria não saber responder se o animal que possui pertence à 
fauna silvestre ou exótica, nem conhecer a sua origem, afirma que se preocupa com a história natural e acredita que as condições oferecidas suprem as suas necessidades básicas (Tabela 5).

Os resultados a respeito do uso de animais para companhia elucidam um descompasso entre percepção e posicionamento ético, bem como a falta de informação. $O$ foco de quem adquire um animal de estimação parece ser mais as gratificações emocionais do que a promoção do bem-estar dos mesmos. A maioria dos entrevistados acredita que as condições oferecidas aos seus animais suprem as necessidades básicas, contudo, deve-se considerar que o que é bom para o tutor necessariamente não será para o animal, tais como: humanização, seleção de raças e mutilações com fins estéticos (BROOM; FRASER, 2010). O cão é a espécie mais utilizada para companhia reflexo do intenso processo de domesticação (REGAN, 2006) e, também, a espécie mais abandonada, decorrente, sobretudo, da compra por impulso, gerando elevada e preocupante densidade populacional de animais errantes, especialmente nos centros urbanos, potenciais transmissores de zoonoses e geradores de acidentes (SANTANA et al., 2004).

Tabela 5. Frequência relativa das principais respostas para as perguntas a respeito do uso de animais para companhia pelo total dos entrevistados, bem como dos relativos às áreas do saber

\begin{tabular}{lrrrrrr}
\hline & Total & ESB & EP & EEH & EN & ECA \\
\hline Motivos & & & & & & \\
Disseram possuir animais de companhia & $65,5^{*}$ & $73^{*}$ & 63 & 58 & 60 & 80 \\
Disseram possuir animal por gostarem & $67^{*}$ & $47^{*}$ & 53 & 45,4 & 33,3 & 0 \\
Disseram possuir animal pela companhia & 22,8 & 36,8 & 5,8 & 18 & 33,3 & 25 \\
$\quad$ Disseram possuir animal por outros motivos & 33,3 & 15,6 & 41 & 34 & 33,3 & 75 \\
(Ganhou; comprou para alguém; recolheu da rua; & & & & & & \\
guarda ou trabalho) & & & & & & \\
Consumo & & & & & & \\
Disseram possuir apenas um animal de companhia & $51^{*}$ & 42 & $53^{*}$ & $73^{*}$ & 33 & 50 \\
Disseram possuir o cão como animal de companhia & $68^{*}$ & $72^{*}$ & $64^{*}$ & $67^{*}$ & $75^{*}$ & 60 \\
Disseram possuir o gato como animal de companhia & 12,5 & 12 & 0,9 & 25 & 12,5 & 0 \\
$\quad$ Disseram possuir aves como animais de companhia & 6,9 & 12 & 0,4 & 0,8 & 0 & 0 \\
Disseram possuir outras espécies como animais de & 12,6 & 0,4 & 23 & 0 & 12,5 & 40 \\
companhia (Porquinho-da-índia, chinchila, tartaruga & & & & & & \\
ou cavalo) & & & & & & \\
Conhecimento & & & & & & \\
Disseram não conhecer a origem do seu animal & 51 & 42 & 59 & 54,5 & 33 & 75 \\
Não souberam responder se o seu animal era silvestre & $68,4^{*}$ & $53^{*}$ & $70,5^{*}$ & $82^{*}$ & 67 & $100^{*}$ \\
ou exótico & & & & & & \\
Disseram conhecer a história natural do seu animal & $70^{*}$ & $74^{*}$ & 59 & 73 & $100^{*}$ & 50 \\
Disseram que oferecem condições para suprir as & $84^{*}$ & $79^{*}$ & $88^{*}$ & 73 & $100^{*}$ & $100^{*}$ \\
necessidades do animal & & & & & & \\
\end{tabular}

Os valores absolutos foram comparados a fim de se testar a homogeneidade nas respostas por meio do teste qui-quadrado, sendo os valores significativamente diferentes $(\mathrm{P}<0,05)$ acompanhados de asterisco. Fonte: elaborada pelos autores. 


\section{A Bioética animal e o ensino de ciências}

O ensino de ciências tanto no nível Fundamental quanto no Médio deve ultrapassar a visão tradicional de desenvolver as óbvias e necessárias habilidades e competências tecno-científicas, e transmitir informações atualizadas (PRAIA; GIL-PÉREZ; VILCHES, 2007; SANTOS; MORTIMER, 2001). As sociedades contemporâneas globalizadas e com sérias questões éticas oriundas de um sistema capitalista, individualista e imediatista demandam mudanças de paradigmas e o desenvolvimento de valores morais que balizem a tomada de decisões para problemas novos, complexos e globais (BAUMAN, 2004). O rápido desenvolvimento tecnológico tem se mostrado incompatível com as primitivas necessidades biológicas do homem e da natureza. Apenas por meio de uma contemplação mais ampla que promova a construção de uma percepção do cidadão como corresponsável pela saúde de todos os habitantes do planeta será possível a retomada de um convívio ético com a natureza. Santos e Mortimer (2001) ressaltam que a decisão responsável implica a consciência dos problemas e dos valores e normas sociais utilizados para orientação da conduta. Políticas públicas presentes desde acordos internacionais, como a Conferência das Nações Unidas sobre o Meio Ambiente e Desenvolvimento até os Parâmetros Curriculares Nacionais (PCN), reclamam a ação dos educadores na construção do cidadão crítico e autônomo. Embora o PCN não fale claramente em ética no uso de animais, aborda, como objetivo do ensino de ciências, a formação de um cidadão participativo social e politicamente, e que contribua ativamente na melhoria da relação com meio ambiente por intermédio do respeito à vida com um todo. Os professores de ciência devem preparar o aluno para perceber as questões éticas como problemas e muni-los de valores e atitudes aplicadas em situações reais que devem ser discutidas em aula (SANTOS; MORTIMER, 2001). As crianças levam para o ambiente escolar representações construídas pela mídia, família e religião. Esses saberes acumulados devem ser considerados no desenvolvimento de ações educativas ambientalmente comprometidas com a formação do indivíduo por meio de uma prática pedagógica criativa, democrática e que dialoga com diferentes gerações e culturas, estimulando a ética nas relações entre os seres vivos (MARTINHO; TALONI, 2007).

Assim, a escola passa ter a missão de equipar os estudantes de ferramentas para refletirem sobre as informações cotidianas e elaborarem suas próprias conclusões (DOURADO; MATOS, 2014), as quais devem ultrapassar o aspecto de empatia pelo ser-vivo, fundamental no direcionamento da área de atuação profissional, levando ao balizamento do seu dever como cidadão independente do papel que irá exercer na sociedade. A maioria significativa dos entrevistados universitários apontou carência de debates das condutas éticas na utilização de animais. Contudo, os acadêmicos da área biológica foram os que evidenciaram maior preocupação, apontando a possibilidade de substituição dos usos, sobretudo das vestimentas. A maioria dos estudantes ainda considera o uso animal como um mal necessário, porém acredita que o mesmo deva ser controlado: seja pela redução do uso, maior respeito, pesquisas, ações diretas, penalidades, controle de compra e venda ou implementação de Comitês de Ética mais rígidos (Tabela 6 ). 
Tabela 6. Frequência relativa das principais respostas quanto às consequências, substituição e soluções para o uso de animais pelo total dos entrevistados, bem como dos relativos às áreas do saber.

\section{$\begin{array}{llllll}\text { Total } & \text { ESB } & \text { EP } & \text { EEH } & \text { EN } & \text { ECA }\end{array}$}

\section{Consequências}

Acreditam que o homem depende dos animais

Acreditam que o uso de animais traz consequências

para o ambiente

Preocupam-se com as consequências do uso dos animais para o ambiente

\section{Substituição}

Apontaram vestimentas como o uso mais fácil de substituição

Apontaram o ensino e pesquisa como o uso mais fácil de substituição

Apontaram o entretenimento como o uso mais fácil de substituição

Apontaram a alimentação como o uso mais fácil de substituição

Apontaram o trabalho como o uso mais fácil de substituição

Apontaram a companhia como o uso mais fácil de substituição

\section{Soluções}

Acreditam que o uso de animais deveria ser mais debatido

Sugerem a conscientização como forma de mudança Sugerem a legislação e fiscalização como forma de mudança

Sugerem outras medidas como forma de mudança

(diminuição do uso, respeito, pesquisas, ações,

$\begin{array}{rrrrrr}94^{*} & 96^{*} & 96^{*} & 89,4^{*} & 90^{*} & 100^{*} \\ 87^{*} & 92^{*} & 81,4 & 89,4^{*} & 90^{*} & 80 \\ & & & & & \\ 67^{*} & 79^{*} & 59 & 50 & 78 & 75\end{array}$

$\begin{array}{llllll}16^{*} & 17,2^{*} & 33^{*} & 26^{*} & 26^{*} & 30^{*}\end{array}$

sensibilização, informação)

Não soube responder

$\begin{array}{rrrrrr}17,2 & 24,5 & 12,3 & 16 & 21 & 0 \\ 16 & 21 & 14 & 9,6 & 15,7 & 20\end{array}$

$\begin{array}{llllll}18,4 & 10,5 & 19,3 & 29 & 21 & 20\end{array}$

$\begin{array}{llllll}17 & 14 & 17,5 & 19,3 & 15,7 & 30\end{array}$

$\begin{array}{llllll}1,14 & 0,1 & 0,1 & 0 & 0 & 0\end{array}$

$94^{*} \quad 100^{*} \quad 89^{*} \quad 89,4^{*} \quad 100^{*} \quad 100^{*}$

$\begin{array}{llllll}14,7 & 22 & 6,4 & 20 & 17 & 0\end{array}$

$\begin{array}{llllll}42 & 44,4 & 45,5 & 25 & 50 & 60\end{array}$

$\begin{array}{llllll}27 & 25,9 & 32,2 & 25 & 17 & 40\end{array}$

Os valores absolutos foram comparados a fim de se testar a homogeneidade nas respostas por meio do teste qui-quadrado, sendo os valores significativamente diferentes $(\mathrm{P}<0,05)$ acompanhados de asterisco.

Fonte: elaborada pelos autores.

\section{Conclusão}

A avaliação global dos resultados do presente estudo evidencia a existência de preocupação ética e apoio para que o tema "ética no uso de animais" e "bem-estar animal" seja mais abordado em ambientes educacionais. Ainda assim, a maioria absoluta dos entrevistados acredita que o uso de animais é justificável. Mesmo não sendo evidente a preocupação com as consequências em todas as áreas analisadas, é importante ressaltar que os entrevistados sabem que elas existem. O fim do uso de animais pelo ser humano parece ser utópico em face de uma sociedade consumista e utilitarista. Porém, a redução e a substituição são válidas sob o 
ponto de vista científico, ecológico, legal e, sobretudo, ético. O fato de a sociedade endossar menos atividades de pesquisa com animais de companhia ou mamíferos de grande porte em detrimento dos roedores ou espécies não mamíferas, impacta no apoio público para conservação de espécies como insetos, répteis ou peixes, demandando mais esforços para a educação (DRISCOLL, 1995). A sociedade tende a ser intolerante com os usos que possuem alternativas, julgando-os frívolos ou desnecessários, como o entretenimento e a vaidade, contudo, apoiam o uso em pesquisas e no ensino, pois os benefícios são maiores do que os custos (KNIGHT et al., 2004, 2009). Segundo Serpell (2004), as atitudes e opiniões da sociedade, somadas a evidências científicas, forçam a elaboração de legislação e políticas públicas; por isso, entender as atitudes e valores da sociedade é fundamental. Logo, é evidente a necessidade de maior discussão desses temas no ensino de ciências para habilitar e instrumentalizar a sociedade na tomada de decisões sobre as aplicações da ciência e, assim, exercer cidadania plena. Esse processo é denominado "alfabetização científica", sendo os valores éticos a base para o julgamento, opção por ideologias, crenças ou teorias. Assim, a educação deve proporcionar os aportes para que os cidadãos compreendam as informações e tomem decisões com base sólidas, contribuindo para construir uma sociedade cujo limite da ciência seja o respeito à biodiversidade e à dignidade de todos os seres vivos (SCHEID, 2011).

Os dados do presente estudo não evidenciam diferenças claras entre a percepção ética sobre a utilização de animais para diferentes finalidades e as áreas de saber avaliadas, sugerindo que as atitudes éticas ultrapassam a afinidade da atuação profissional. Esse resultado fundamenta a hipótese do presente estudo, de que a pouca relação com os mecanismos envolvidos com a vida, objeto de trabalho da área biológica, faria com que os acadêmicos e os profissionais dessa área mostrassem maior compreensão e preocupação com o bem-estar dos animais. No entanto, o resultado conduz a uma interpretação importante de que a falta de informação e conscientização parecem ser componentes essenciais para mudança nas atitudes éticas. A preocupação e a reflexão sobre as questões éticas contemporâneas não devem ser tratada apenas no Ensino Superior, mas os valores devem ser paulatinamente construídos desde o Ensino Básico e, concomitantemente, com a incorporação de conceitos sobre história natural, tecnologia e sociedade. Contribuindo, desta forma, com a formação profissional mais consistente e consciente. Uma vez que o universo a ser trabalhado é homogêneo quanto a suas percepções, remete a elaboração de programas globais de sensibilização e conscientização que despertem a visão do animal como ser senciente. Esse estudo apresenta uma visão global, contudo, o aprofundamento em cada um dos usos é extremamente necessário para que sejam elaboradas políticas de intervenção mais contundentes.

\section{Agradecimentos}

Agradecimento especial aos respondentes, cuja dedicação e paciência foram fundamentais para a realização deste trabalho. 
Fischer, M. L.; Tamioso, P. R.

\section{Referências}

AGORAMOORTHY, G. Ethics and welfare in southeast Asian zoos. Journal of Applied Animal Welfare Science, Philadelphia, v. 7, n. 3, p. 189-195, 2004.

AL-FAYEZ, G. et al. Companion animal attitude and its family pattern in Kuwait. Society $\boldsymbol{\&}$ Animals, Leiden, v. 11, n. 1, p. 17-28, 2003.

ARAGÃO, M. J. Civilização animal: a etologia numa perspectiva evolutiva e antropológica. Pelotas: USB, 2006.

BAUMAN, Z. Amor líquido: sobre a fragilidade dos laços humanos. Rio de Janeiro: Zahar, 2004.

BARDIN, L. Análise de conteúdo. Lisboa: Edições 70, 1982.

BRASIL. Constituição (1988). Constituição: República Federativa do Brasil. Brasília:

Senado Federal, 1988. Disponível em: < http://www.planalto.gov.br/ccivil_03/constituicao/ constituicao.htm> Acesso em: 31 mar. 2014.

Lei no 9.605, de 12 de fevereiro de 1998. Dispõe sobre as sanções penais e administrativas derivadas de condutas e atividades lesivas ao meio ambiente, e dá outras providências. Diário Oficial da União, Brasília, 13 fev. 1998.

Lei $n^{\circ} 11.794$, de 8 de outubro de 2008. Regulamenta o inciso VII do $\int 1^{\circ}$ do art.

225 da Constituição Federal, estabelecendo procedimentos para o uso científico de animais; revoga a Lei no 6.638, de 8 de maio de 1979; e dá outras providências. Diário Oficial da União, Brasília, 9 out. 2008. Disponível em: < http://www.planalto.gov.br/ccivil_03/_ ato2007-2010/2008/lei/111794.htm>. Acesso em: 31 mar. 2014.

BROOM, D. M.; FRASER, A. F. Comportamento e bem-estar de animais domésticos. 4. ed. São Paulo: Manole, 2010.

CHALFUN, M. Animais, manifestações culturais e entretenimento, lazer ou sofrimento? In: CONGRESSO MUNDIAL DE BIOÉTICA E DIREITO ANIMAL, 1., 2008, Salvador. Disponível em: <http://www.abolicionismoanimal.org.br/artigos/ animaismanifestaesculturaiseentretenimentolazerousofrimento.pdf $>$. Acesso em: 1 abr. 2011.

COELHO, J. G. Pessoalidade e cidadania em animais: o problema das outras mentes. In:

MÍDIA e cidadania: conexões emergentes. São Paulo: Cultura Acadêmica, 2012. p. 171-192.

COLEMAN, G.; HAY, M. Consumer attitudes and behaviour relevant to pork production. In: PROCEEDINGS of the Australian Association of Pig Veterinarians. Eight Mile Plains: Australian Association of Pig Veterinarians, 2004. p. 133-142.

DAVEY, G. Chinese university student's attitudes toward the ethical treatment and welfare of animals. Journal of Applied Animal Welfare Science, Philadelphia, v. 9, n. 4, p. 289-297, 2006. 
Bioética ambiental: concepção de estudantes universitários ...

DOURADO, L.; MATOS, L. A problemática dos organismos geneticamente modificados e a formação científica do cidadão comum: um estudo com alunos de escolas portuguesas. Ciência \& Educação, Bauru, v. 20, n. 2, p. 279-296, 2014. Disponível em: < http:/ /dx.doi. org/10.1590/1516-73132014000400005>. Acesso em: 19 nov. 2015.

DRISCOLL, J. W. Attitudes toward animals: species ratings. The White Horse Press, Cambridge, v. 3, n. 2, p. 139-150, 1995.

FISCHER, M. L.; OLIVEIRA, G. M. Ética no uso de animais: a experiência do comitê de ética no uso de animais da Pontifícia Universidade Católica do Paraná. Estudos de Biologia, Curitiba, v. 34, n. 83, 2012. Disponível em: < http://www2.pucpr.br/reol/index.php/ BS?dd1 $=7337 \& d d 99=$ view $>$. Acesso em: 19 nov. 2015.

FISCHER, M. L.; TAMIOSO, P. R. Percepção e posicionamento de estudantes e professores de diferentes áreas do saber perante o uso de animais no ensino e pesquisa. Estudos de Biologia, Curitiba, v. 35, n. 84, p. 85-98, 2013. Disponível em: <http:/ /www2.pucpr.br/ reol/index.php/BS?dd1=7846\&dd99=view>. Acesso em: 19 nov. 2015.

FELIPE, S. T. Fundamentação ética dos direitos animais: o legado de Humphry Primatt. Revista Brasileira de Direito Animal, Salvador, v. 1, n. 1, p. 207-229, 2006a. Disponível em: < http://www.portalseer.ufba.br/index.php/RBDA/article/view/10249/7306>. Acesso em: 19 nov. 2015.

. Valor inerente e vulnerabilidade: critérios éticos não-especistas na perspectiva de Tom Regan. ethic@, Florianópolis, v. 5, n. 3, p. 125-146, 2006b. Disponível em: <https:// periodicos.ufsc.br/index.php/ethic/article/view/24877>. Acesso em: 19 nov. 2015.

GAGLEAZZI, U. A. et al. Caracterização do consumo de carnes no Brasil. Revista Nacional da Carne, São Paulo, v. 27, n. 310, p. 35-46, 2002.

GOMES, C. C.; OLIVEIRA, R. L. D. O tráfico internacional de animais: tratamento normativo e a realidade brasileira. Direito e Liberdade, Natal, v. 14, n. 2, p. 29-42, 2013.

HAIDT, J. The emotional dog and its rational tail: a social intuitionist approach to moral judgment. Psychological Review, Washington, v. 108, n. 4, p. 814-834, 2001.

HERZOG, H. A.; GOLDEN, L. L. Moral emotions and social activism: the case of animal rights. Journal of Social Issues, Hoboken, v. 65, n. 3, p. 485-498, 2009.

HÖTZEL, M. J.; MACHADO FILHO, L. C. P. Bem-estar animal na agricultura do século XXI. Revista de Etologia, São Paulo, v. 6, n. 1, p. 3-16, 2004. Disponível em: < http:/ /www. etologiabrasil.org.br/sbet/revista/Vol_6_1_003.pdf>. Acesso em: 19 nov. 2015.

KELLERT, S. R.; BERRY, J. K. Knowledge, affection and basic attitudes towards animals in American society. Springfield: US Department of the Interior, Fish and Wildlife Service, 1982.

KNIGHT, S. et al. Attitudes towards animal use and belief in animal mind. Anthrozoos, Abingdon, v. 17, n. 1, p. 43-62, 2004. 
Fischer, M. L.; Tamioso, P. R.

KNIGHT, S. et al. "Science versus human welfare?: understanding attitudes toward animal use”. Journal of Social Issues, Hoboken, v. 65, n. 3, p. 463-83, 2009.

MARANHÃO, R. P. A. et al. Afecções mais freqüentes do aparelho locomotor dos eqüídeos de tração no município de Belo Horizonte. Arquivo Brasileiro de Medicina Veterinária e Zootecnia, Belo Horizonte, v. 58, n. 1, p. 21-27, 2006. Disponível em: < http://dx.doi. org/10.1590/S0102-09352006000100004>. Acesso em: 19 nov. 2015.

MARINO, L. et al. Do zoos and aquariums promote attitude change in visitors?: a critical evaluation of the American zoo and aquarium study. Society and Animals, Leiden, v. 18, p. 126-138, 2010. Disponível em: < http://animalsandsociety.org/assets/322_ marinoazastudy.pdf>. Acesso em: 19 nov. 2015.

MARTINHO, L. R.; TALAMONI, J. L. B. Representações sobre meio ambiente de alunos da quarta série do ensino fundamental. Ciência \& Educação, Bauru, v. 13, n. 1, p. 1-13, 2007. Disponível em: < http://dx.doi.org/10.1590/S1516-73132007000100001>. Acesso em: 19 nov. 2015.

MEU pai não teve culpa, diz menino que perdeu braço após ataque de tigre no zoo. $\mathbf{O}$ Globo, Rio de Janeiro, 10 ago. 2014. Disponível em: <http://oglobo.globo.com/brasil/meupai-nao-teve-culpa-diz-menino-que-perdeu-braco-apos-ataque-de-tigre-no-zoo-13556209>. Acesso em: 6 out. 2015.

MORRIS, D. O contrato animal. Rio de Janeiro: Record, 1990.

MUÑOZ, D. R. Bioética: a mudança da postura ética. Revista Brasileira de

Otorrinolaringologia, São Paulo, v. 70, n. 5, p. 578-579, 2004. Disponível em: <http:// dx.doi.org/10.1590/S0034-72992004000500001>. Acesso em: 19 nov. 2015.

NICKELL, D.; HERZOG, A. H. Ethical ideology and moral persuasion: personal moral philosophy, gender, and judgments of pro - and anti - animal research propaganda. Society and Animals, Leiden, v. 4, n. 1, p. 53-64, 1996.

NORDSTROM, P. A. et al. Assessing student attitudes toward animal welfare, resource, use, and food safety. Journal of Agricultural Education, West Lafayette, v. 41, n. 3, p. 31-39, 2000. Disponível em: <http://www.jae-online.org/attachments/article/437/41-03-31.pdf>. Acesso em: 19 nov. 2015.

OLIVEIRA, L. M. et al. Carroceiros e eqüídeos de tração: um problema sócio-ambiental. Caminhos de Geografia, Uberlândia, v. 8, n. 24, p. 204-216, 2007.

PETROIANU, A. Aspectos éticos na pesquisa em animais. Acta Cirúrgica Brasileira, São Paulo, v. 11, n. 3, p. 157-64, 1996.

PHILLIPS, C. How does pain rank as an animal welfare issue? In: AUSTRALIAN ANIMAL WELFARE STRATEGY SCIENCE SUMMIT ON PAIN AND PAIN MANAGEMENT, 2007, Melbourne. Proceedings... Disponível em: <http://www.australiananimalwelfare. com.au/app/webroot/files/upload/files/clive-phillips.pdf>. Acesso em: 19 nov. 2015. 
Bioética ambiental: concepção de estudantes universitários ...

PHILLIPS, C. J. C.; McCULLOUGH, S. Student attitudes on animal sentience and use of animals in society. Journal of Biological Education, Philadelphia, v. 40, n. 1, p. 1-8, 2005.

PIFER, L. K. Exploring the gender gap in young adults's attitudes about animal research. Society and Animals, Leiden, v. 4, n. 1, p. 37-52, 1996. Disponível em: <http:// animalsandsociety.org/assets/library/310_s413.pdf>. Acesso em: 19 nov. 2015.

PLOUS, S. Psychological mechanisms in the human use of animals. Journal of Social Issues, Hoboken, v. 49, n. 1, p. 11-52, 1993.

PRAIA, J.; GIL-PÉREZ, D.; VILCHES, A. O papel da natureza da ciência na educação para a cidadania. Ciência \& Educação, Bauru, v. 13, n. 2, p. 141-156, 2007. Disponível em: <http://dx.doi.org/10.1590/S1516-73132007000200001>. Acesso em: 19 nov. 2015.

PROJETO ESPERANÇA ANIMAL. Animais em circos. Disponível em: < http://www. pea.org.br/Crueldade/circos/index.htm>. Acesso em: 20 nov. $2015 \mathrm{a}$.

PROJETO ESPERANÇA ANIMAL. Animais usados para tração. Disponível em: < http:// www.pea.org.br/crueldade/tracao/>. Acesso em: 20 nov. 2015b.

RAMASWAMY, N. S. Draught animal welfare. Applied Animal Behaviour Science, Amsterdam, v. 59, n. 1-3, p. 73-84. 1998. Disponível em: <http://dx.doi.org/10.1016/ S0168-1591(98)00122-1>. Acesso em: 19 nov. 2015.

REGAN, T. Jaulas vazias. Porto Alegre: Lugano, 2006.

SANDERS. S.; FEIJÓ. A. G. S. Uma reflexão sobre animais selvagens cativos em zoológicos na sociedade atual. Uma reflexão sobre animais selvagens cativos em zoológicos na sociedade atual. In: CONGRESSO INTERNACIONAL TRANSDISCIPLINAR AMBIENTE E DIREITO, 3., 2007, Porto Alegre. Anais... Porto Alegre: PUC RS, 2007.

SANDOE, P.; CHRISTIANSEN, S. B. Animal futures: the changing face of animal ethics. In: MILLAR, K.; WEST, P. H.; NERLICH, B. (Ed.). Ethical futures: bioscience and food horizons. Wageningen: Wageningen Academics, 2009. p. 27-33.

SANTANA, L. R. et al. Posse responsável e dignidade dos animais. In: CONGRESSO INTERNACIONAL EM DIREITO AMBIENTAL, 8., 2004, São Paulo. Anais... São Paulo: Instituto O Direito por um Planeta Verde, 2004.

SANTOS, W. L. P.; MORTIMER, E. F. Tomada de decisão para ação social responsável no ensino de ciências. Ciência \& Educação, Bauru, v. 7, n. 1, p. 95-111, 2001. Disponível em: <http://dx.doi.org/10.1590/S1516-73132001000100007>. Acesso em: 19 nov. 2015.

SCHEID, N. M. J. Temas controversos no ensino de ciências: apontamentos de natureza ética. Diálogo, Canoas, v. 19, n. 1, p. 65-79, 2011.

SERPELL, J. A. Factors influencing human attitudes to animals and their welfare. Animal Welfare, St Albans, v. 13, suppl. 1, p. 145-151, 2004.

SIGNAL, T. D.; TAYLOR, N. Attitude to animals and empathy: comparing animal protection and general community samples. Anthrozoos, Abingdon, v. 20, n. 2, p. 125-130, 2007. 
Fischer, M. L.; Tamioso, P. R.

SILLA, V. C. B.; SANS, E. C. O.; MOLENTO, C. F. M. An estimation of the extent of animal use in research in Brazil, as determined by bibliographic sampling from journals published in the state of Paraná. Alternatives to Laboratory Animals, Nottingham, v. 38, n. 1, p. 29-37, 2010.

SILVA, J. M. Do senciocentrismo ao holismo ético: perspectivas sobre o valor da bioesfera. In: BARBOSA, A. et al. (Ed.). Gravitações bioéticas. Lisboa: Centro de Bioética, Faculdade de Medicina da Universidade de Lisboa, 2012. p. 123-145.

SINGER, P. Libertação animal. Porto Alegre: Lugano, 2004.

STAFFORD, K. The human-animal bonds. In: INTERNATIONAL ANIMAL WELFARE CONFERENCE, 2007, Gold Coast, Australia. Proceedings... Canberra: Department of Agriculture, Fisheries and Forestry, 2008. Disponível em: <http://www. australiananimalwelfare.com.au/app/webroot/files/upload/files/The $\% 20$ human-animal $\% 20$ bond.pdf>. Acesso em: 20 nov. 2015.

TINOCO, I. A. P. Lei Arouca: avanço ou retrocesso? In: CONGRESSO MUNDIAL DE BIOÉTICA E DIREITO DOS ANIMAIS, 1., 2008, Salvador. Disponível em: <http://www. abolicionismoanimal.org.br/artigos/leiaroucaavanoouretrocesso.pdf $>$. Acesso em: 30 maio 2012.

WEBSTER, J. Animal welfare: limping towards eden. Oxford: Blackwell, 2005.

WORLD ANIMAL PROTECTION BRASIL. Animais de trabalho. [2007]. Disponível em: <http://www.mosaicoanimal.org.br/Images/M\%C3\%B3dulo_21_Animais_de_ trabalho_tcm49-29404.pdf>. Acesso em: 20 jun. 2010.

ZIMMER, C. O Livro de ouro da evolução. Rio de Janeiro: Ediouro, 2003.

Artigo recebido em 14/08/2014. Aceito em 04/10/2015.

Endereço para contato:

Rua Imaculada Conceição, 1155, Prado Velho, CEP 80215-901,

Curitiba, PR, Brasil. 